\title{
Uma nova espécie de Schizomyia (Diptera, Cecidomyiidae), indutora de galhas nos botões florais de Jacquemontia holosericea (Convolvulaceae)
}

\author{
Valéria Cid Maia ${ }^{1} \&$ Walter Santos de Araújo ${ }^{2}$
}

\begin{abstract}
${ }^{1}$ Departamento de Entomologia, Museu Nacional, Quinta da Boa Vista, São Cristóvão, 20940-040 Rio de Janeiro-RJ, Brasil. maiavcid@acd.ufrj.br ${ }^{2}$ Laboratório de Entomologia, Departamento de Biologia Geral, Campus II, Caixa Postal 131, 74001-970 Goiânia-GO, Brasil. walterbioaraujo@yahoo.com.br
\end{abstract}

\begin{abstract}
A new species of Schizomyia (Diptera, Cecidomyiidae), inducing galls on flower buds of Jacquemontia holosericea (Convolvulaceae). Schizomyia santosi, a new species of Cecidomyiidae (Diptera), which induces flower bud galls on Jacquemontia holosericea (Convolvulaceae), is described as larva, pupa, and adult (male and female). Illustrations from the main morphological characters are given.
\end{abstract}

KEYWORDS. Gall; Neotropical region; restinga; taxonomy.

RESUMO. Uma nova espécie de Schizomyia (Diptera, Cecidomyiidae), indutora de galhas nos botões florais de Jacquemontia holosericea (Convolvulaceae). Schizomyia santosi, uma nova espécie de Cecidomyiidae (Diptera), que induz galhas nos botões florais de Jacquemontia holosericea (Convolvulaceae) é descrita nas fases de larva, pupa e adulto (macho e fêmea). Ilustrações dos principais caracteres morfológicos são apresentadas.

PALAVRAS-CHAVE. Galha; região neotropical; restinga; taxonomia.

Restingas são ambientes com grande riqueza de galhas de insetos, sendo os Cecidomyiidae (Diptera) o principal grupo galhador tanto em abundância, como em freqüência e diversidade (Maia 2001). Porém, na Região Neotropical, a taxonomia dessa família, ainda é pouco estudada e segundo Gagné (1994) é inestimável o número de espécies não descritas.

Maia (2001) registrou a presença de galhas de Schizomyia sp. (Diptera, Cecidomyiidae) nos botões florais de Jacquemontia holosericea (Weinman) O’Donnel (Convolvulaceae), na restinga da Barra de Maricá e de Itaipuaçú (Maricá, RJ).

Jacquemontia holosericea distribui-se no Ceará, Rio de Janeiro, São Paulo e Santa Catarina. No estado do Rio de Janeiro, ocorre na faixa litorânea que se estende desde Arraial do Cabo até Maricá, da Ponta do São João (na entrada da Baía de Guanabara) até o Morro do Catete e da Ponta do Picão até Mangaratiba. Na restinga de Barra de Maricá e de Itaipuaçu, essa planta é abundante, sendo facilmente encontrada nos cordões arenosos, próximos ou afastados do mar, nos "scrub" de Palmae, caracterizados pela cobertura baixo-arbustiva e aberta, com até 1,5 m de altura, dominada por Alagoptera arenaria (Gomes) O. Ktze (Arecaceae) (Araújo \& Henriques 1984).

As galhas nos botões florais ocorrem no período de julho a dezembro, e o número de larvas cecidógenas por galha varia de 1 a 3 (Maia 2001). Externamente, o botão atacado pouco se distingue do botão sadio, a não ser por adquirir uma forma levemente mais alongada (fig. 29 in Maia 2001).

Estudos morfológicos prévios indicaram que o galhador é uma espécie nova de Schizomyia Kieffer, 1889 (Diptera, Cecidomyiidae), descrita nesse artigo.
Schizomyia é um gênero cosmopolita, com 50 espécies conhecidas associadas a 24 famílias de plantas (Gagné 2004, 2008; Maia \& Fernandes 2005; Maia \& Oliveira 2007). Oito espécies são descritas na Região Neotropical, quatro delas no Brasil: S. manihoti Tavares, 1925; S. tиiuiu Urso-Guimarães \& Amorim, 2002; S. macropillata Maia, 2005 e S. spherica Maia \& Oliveira, 2007. Das 50 espécies conhecidas, apenas duas estão associadas à Convolvulaceae: S. cheriani Mani, 1936 (da Índia) e S. ipomoeae Felt, 1910 (de Guadalupe e St. Vincent). Schizomyia caracteriza-se por apresentar palpo com quatro artículos, ovipositor em forma de agulha e larva com quatro pares de papilas terminais (Gagné 1994).

Gagné \& Menjivar 2008 dividiu as espécies ocidentais em dois grupos, com base em caracteres das garras e empódio, um com garras tarsais em forma de gancho e empódio aproximadamente do mesmo comprimento que as garras e o outro com garras tarsais falciformes e empódio com 1/3 do comprimento das garras ou menos. A espécie nova enquadrase no primeiro grupo, constituído até então por 10 espécies: $S$. altifila Felt, 1907a; S. ipomoeae Felt, 1910b, S. macrofila Felt, 1907d, S. macropillata Maia, 2005, S. petiolicola Felt, 1908b, S. serjaniae Möhn, 1960c, S. stachytarphetae Barnes, 1932, S. tиіміи Urso-Guimarães \& Amorim, 2002, S. umbellicola Osten Sacken, 1878, S. viburni Felt 1908b.

Com a descrição dessa espécie nova, o gênero passa a incluir 51 espécies, sendo nove na Região Neotropical (cinco das quais descritas do Brasil), e o número de espécies conhecidas associadas a Convolvulaceae eleva-se para três. 


\section{MATERIALE MÉTODOS}

O material examinado foi obtido de um levantamento de galhas realizado entre 1998 e 2000, em áreas de restinga no Município de Maricá, RJ, Brasil. As larvas e pupas foram obtidas através da dissecação das galhas, em laboratório, com auxílio de estilete e pinça, e foram conservadas em álcool etílico $70 \%$. Para obtenção dos adultos, o restante do material foi acondicionado em potes plásticos etiquetados, tampados com tela de nylon e contendo papel umedecido ao fundo. Quando emergiram, os adultos ainda vivos, foram transferidos para frascos com álcool 70\%. Machos, fêmeas, pupas e larvas foram montados em lâminas permanentes de acordo com a metodologia de Gagné (1994).

Todos os exemplares, incluindo os tipos, estão depositados na coleção de Diptera do Museu Nacional, Rio de Janeiro (MNRJ).

\section{RESULTADOS}

\section{Schizomyia santosi sp. nov.}

(Figs. 1-20)

Adulto. Comprimento do corpo: macho: 1,55-2,43 mm $(\mathrm{n}=5)$; fêmea (do vértice à margem posterior do tergito 8): 2,02,55 $(\mathrm{n}=5)$.

Cabeça (Fig. 1). Olhos com facetas hexagonais, contíguos no ápice. Antena: escapo ob-cônico; pedicelo globuloso, ambos com cerdas; flagelômeros cilíndricos com haste nua e curta em ambos os sexos; flagelômeros 1 e 2 unidos, 11 flagelômeros na fêmea e 12 no macho; flagelômeros 9-11 progressivamente menores na fêmea (Fig. 2) e flagelômeros 912 similares em tamanho no macho (Fig. 3); circunfilos sinuosos no macho (Fig. 4) e lineares na fêmea (Fig. 5). Frontoclípeo com 13-24 cerdas $(n=5)$. Labro triangular com 3 pares de cerdas ventrais. Labelos hemisféricos, cada qual com várias cerdas laterais e 2 cerdas mesais curtas. Palpo com 4 segmentos cilíndricos, crescentes em comprimento, todos com cerdas; no macho: primeiro segmento 2,0 vezes mais longo que o segundo, segundo segmento mais largo que os demais, terceiro segmento 1,6 vezes mais longo que o segundo, e quarto segmento aproximadamente do mesmo comprimento que o terceiro; na fêmea: primeiro segmento 1,7 vezes mais longo que o segundo, segundo segmento mais largo que os demais, terceiro segmento 1,3 vezes mais longo que o segundo, e quarto segmento 1,7 vezes mais longo que o terceiro.

Tórax. Anepisterno com cerdas, demais pleuras nuas. Asas (Fig. 6). Comprimento (do árculo até o ápice): macho, 1,15-1,5
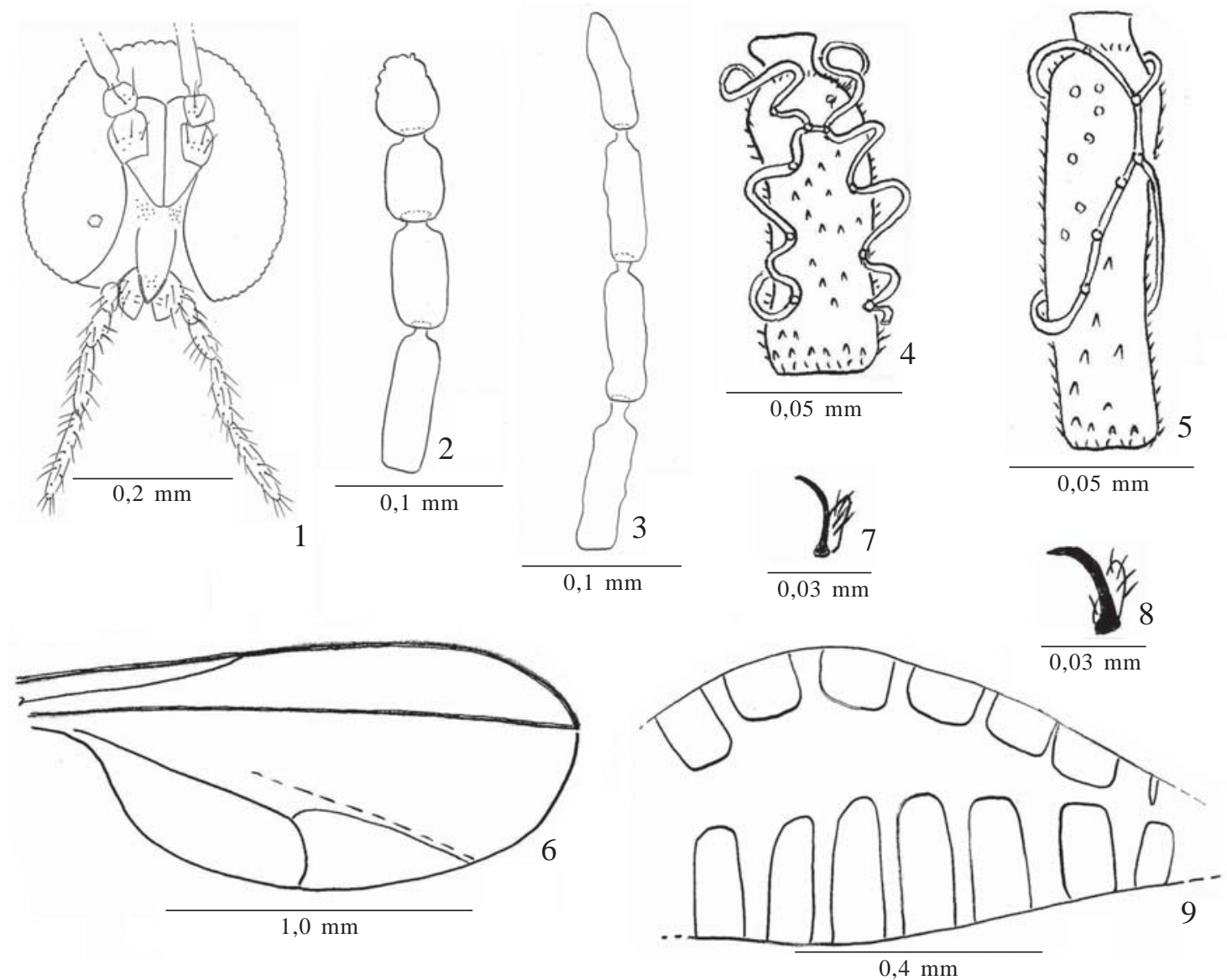

Figs. 1-9. Schizomyia santosi sp. nov.: 1, macho, cabeça, vista frontal; 2, fêmea, flagelômeros 9-11; 3, macho, flagelômeros 9-12; 4, macho, flagelômero 4; 5, fêmea, flagelômero 4; 6, fêmea, asa; 7, macho, perna 3, garra tarsal e empódio; 8, fêmea, perna 3, garra tarsal e empódio; 9. macho, segmentos abdominais $5-8$, vista ventrolateral. 


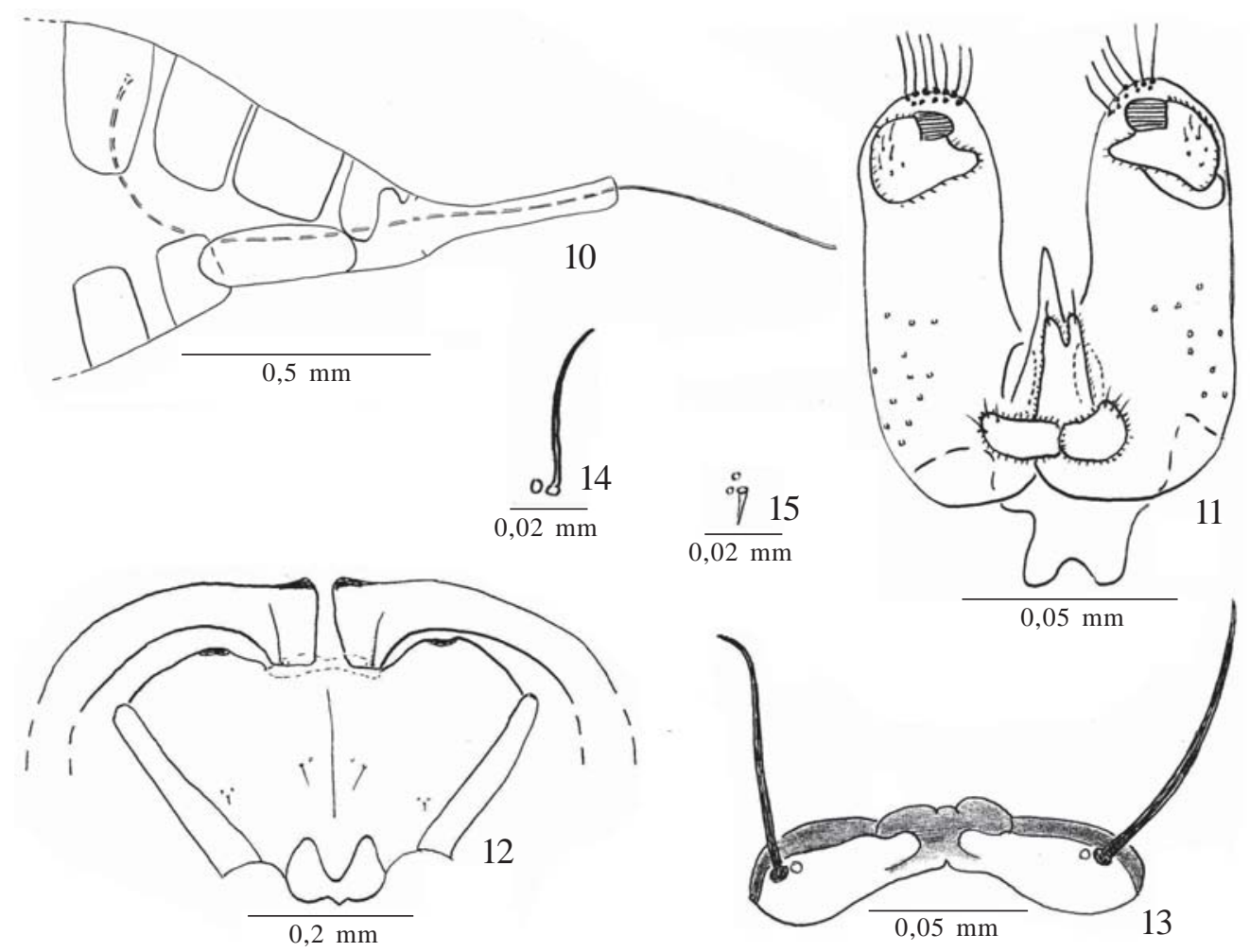

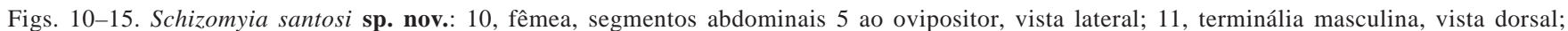
12, pupa, cabeça, vista frontal; 13, pupa, placa dorsal com cerda apical; 14, pupa, papilas faciais inferiores; 15, pupa, papilas faciais laterais.

$\mathrm{mm}$ ( $\mathrm{n}=5)$; fêmea: 1,5-1,75 mm (n=5); R1 encontrando C antes da metade do comprimento da asa; R5 ligeiramente curva, encontrando $\mathrm{C}$ um pouco antes do ápice da asa; M3 presente; $\mathrm{CuA}$ bifurcada; $\mathrm{CuP}$ ausente. Primeiro tarsômero sem esporão; garras tarsais simples curvas após a metade de seu comprimento; empódio bem desenvolvido; garras da fêmea nitidamente mais robustas que no macho (Figs. 7 e 8).

Abdome. Macho (Fig. 9): tergitos 1-7 retangulares com uma fileira de cerdas caudais, algumas cerdas laterais, escamas no restante de sua extensão e 1 par de sensilas tricóides basais. Tergito 8 estreito, linear, sem cerdas ou escamas, com 1 par de sensilas tricóides basais. Esternitos 2-7 retangulares com uma fileira de cerdas caudais, algumas cerdas laterais, cerdas abundantes mesalmente, escamas no restante de sua extensão e 1 par de sensilas tricóides basais; esternito 8 ovóide com uma fileira de cerdas caudais, algumas cerdas laterais, cerdas e escamas esparsas no restante de sua extensão e 1 par de sensilas tricóides basais. Fêmea (Fig. 10): tergitos 1-7 como no macho; tergito 8 esclerotizado, com uma reentrância lateral, sem cerdas ou escamas e com 1 par de sensilas tricóides basais; esternitos 2-6 como no macho, esternito 7 com uma fileira de cerdas caudais, algumas cerdas laterais, cerdas e escamas dispersas no restante de sua extensão e 1 par de sensilas tricóides basais; esternito 8 não esclerotizado.

Terminália masculina (Fig. 11). Gonocoxito amplo, três vezes mais longo que largo, com cerdas em toda a sua extensão, porém mais concentradas no ápice; gonóstilo retangular, duas vezes e meia mais longo do que largo e com cerdas; cercos reniformes, separados e com cerdas; hipoprocto bilobado com cerdas; parâmeros cilíndricos, reduzidos e edeago triangular afilando gradativamente para o ápice.

Ovipositor (Fig. 10). Protráctil, com aproximadamente 1,55 $\mathrm{mm}$ de comprimento quando totalmente protraído.

Pupa. Fracamente esclerotinizada. Comprimento do corpo: 2,25-3,0 mm ( $\mathrm{n}=5)$. Cabeça (Fig. 12): Chifre antenal triangular, pouco desenvolvido; cerda apical com aproximadamente 0,07 $\mathrm{mm}$ de comprimento $(\mathrm{n}=1)$ (Fig. 13); espinhos frontais ausentes; dois pares de papilas faciais inferiores, um par com cerda de aproximadamente $0,05 \mathrm{~mm}$ de comprimento $(\mathrm{n}=1)$ e o outro nu (Fig. 14); três pares de papilas faciais laterais, um par com cerda de aproximadamente $0,02 \mathrm{~mm}$ de comprimento $(\mathrm{n}=1)$ e os outros dois nus (Fig, 15). Margem cefálica superior espessada lateralmente. Tórax. Espiráculo protorácico fortemente esclerotizado, alongado, afilando para o ápice e levemente curvo, com aproximadamente $1,4 \mathrm{~mm}$ de comprimento (n=1) (Fig. 16). Abdômen (Fig, 17). Segmentos 3 a 9 com espinhos apenas na parte discal dos tergitos, de comprimento crescente.

Larva. Corpo alongado, cilíndrico, afilando em ambas as extremidades. Comprimento do corpo: 2,2-2,84 mm (n=4). Tegumento granuloso. Espátula protorácica bi denteada, com $0,14 \mathrm{~mm}$ de comprimento $(\mathrm{n}=4)$; dentes apicais afastados entre si e haste alongada; dois grupos de três papilas laterais de cada lado (em cada grupo: duas papilas com cerda e uma nua) 


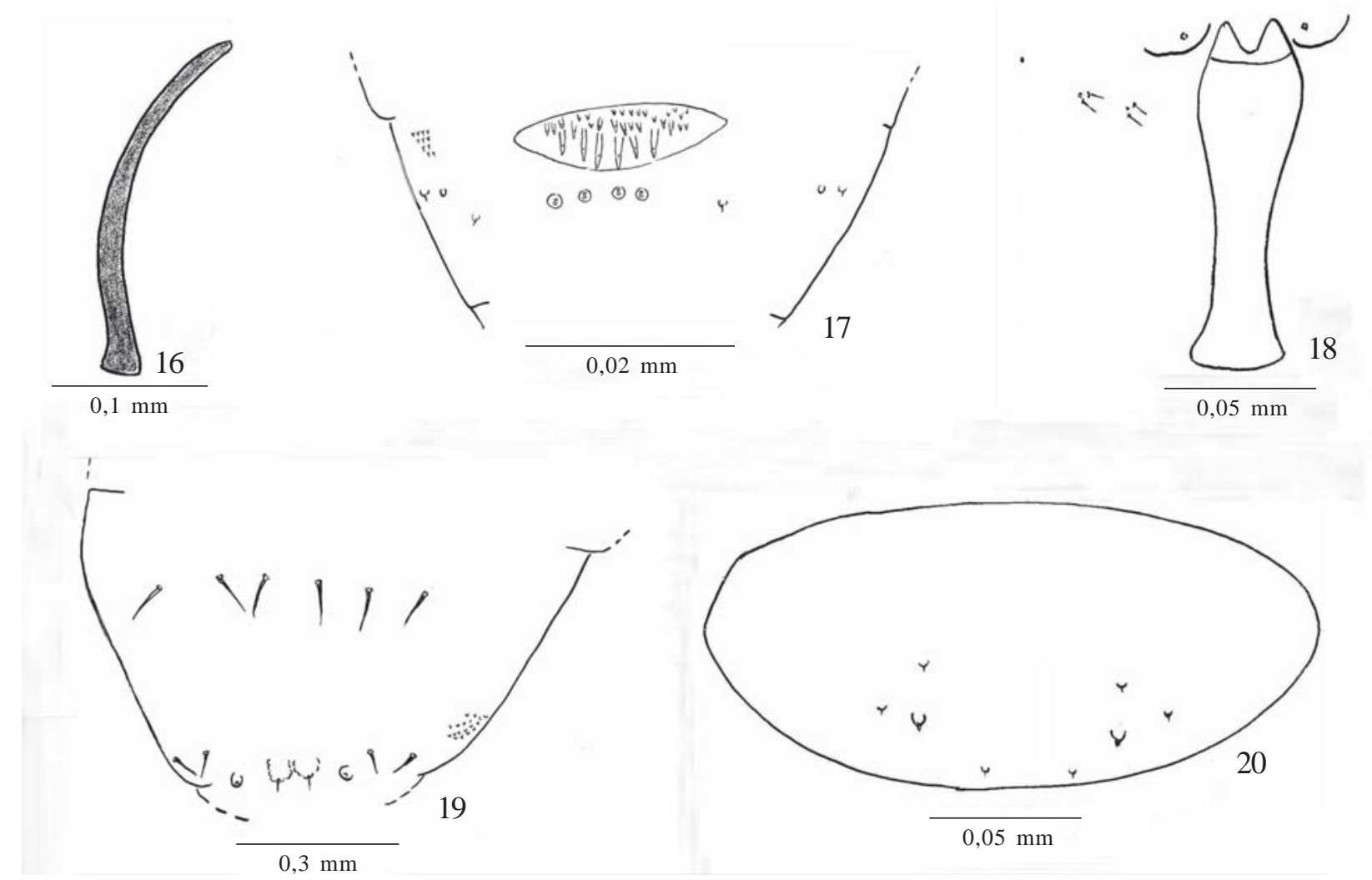

Figs. 16-20. Schizomyia santosi sp. nov.: 16, pupa, espiráculo protorácico; 17, pupa, segmento abdominal 8, vista dorsal; 18, larva, espátula e papilas laterais, vista ventral; 19, larva, segmentos abdominais 7 e 8, vista dorsal; 20, larva, segmento terminal, vista_dorsal.

(Fig. 18); segmento abdominal 8 (Fig. 19) com duas projeç̃oes mesais entre os espiráculos, cada qual com uma papila dorsal com cerda; 2 papilas dorsais com cerda, cada qual situada entre o espiráculo e a margem lateral do segmento e 1 par de papilas pleurais com cerda; segmento terminal convexo, com quatro pares de papilas (um par corniforme e três pares cerdiformes) (Fig. 20).

Material examinado. Holótipo macho. BRASIL, Rio de Janeiro: Maricá (Restinga da Barra de Maricá), 20.IX.2000. Maia \& Azevedo leg. (MNRJ). Parátipos: mesma localidade, data e coletor: 08 machos, 12 fêmeas, 7 exúvias pupais e 4 larvas; mesma localidade: 2 fêmeas, 01.VIII.1998, V.C. Maia leg.; (Restinga de Itaipuaçú): 5 larvas, 1.VIII.1998, V. Maia leg. (MNRJ). Obtidos de galhas desenvolvidas no botão floral de Jacquemontia holosericea (Fig, 29, p. 599, em Maia 2001).

Etimologia. O epíteto específico é uma homenagem ao Dr. Benedito Baptista dos Santos (Universidade Federal de Goiás).

Comentários. Schizomyia santosi é a única espécie do gênero cuja fêmea possui apenas 11 flagelômeros. Trata-se da primeira espécie de Schizomyia associada ao gênero Jacquemontia Choisy. Dentre as espécies conhecidas, $S$. santosi aproxima-se mais a $S$. ipomoeae, diferindo nos seguintes caracteres:

1. Os machos de $S$. santosi têm de 1,5 a 2,4 mm de comprimento do corpo, já os de $S$. ipomoeae são um pouco menores, com 1,2 mm. O mesmo observa-se em relação às fêmeas (de 2,0 a 2,5 $\mathrm{mm}$ em $S$. santosi e com $1,75 \mathrm{~mm}$ em $S$. ipomoeae).

2. Com relação às proporções dos segmentos do palpo dos machos: em $S$. santosi, o segundo segmento é duas vezes mais longo que o primeiro, e o quarto é aproximadamente do mesmo comprimento que o terceiro; já em $S$. ipomoeae, o segundo é apenas um pouco maior que o primeiro e o quarto é 1,5 vezes mais longo que o terceiro.

3. A nervura R5, em $S$. santosi, encontra $\mathrm{C}$ um pouco antes do ápice da asa. Diferentemente, em S. ipomoeae, R5 encontra $\mathrm{C}$ logo após o ápice.

4. A pupa de $S$. santosi possui espinhos dorsais nos segmentos abdominais 3 a 9, já a de $S$. ipomoeae nos segmentos abdominais 2 a 8 .

5. O gonocoxito de $S$. ipomoeae é robusto e o edeago é curto, segundo Felt 1910, enquanto que em S. santosi o gonocoxito é mais aparentemente mais delicado e o edeago é claramente mais longo que o hipoprocto e cerco. No entanto, cabe acrescentar que Felt 1910 não apresentou ilustrações da terminália masculina. As informações aqui discutidas baseiam-se na descrição original de S. ipomoeae, e os conceitos de "robusto" e "curto" podem ser pouco precisos, uma vez que não foram aferidas as medidas nem absolutas, nem relativas. 
Agradecimentos. A Dra. Maria Antonieta Pereira de Azevedo (Museu Nacional, Universidade Federal do Rio de Janeiro) pela ajuda nos trabalhos de campo e ao CNPq (Proc. 301197/2007-5 e 472084/20070) pelo suporte financeiro.

\section{REFERÊNCIAS}

Araújo, D. S. D \& R. P. B. Henriques. 1984. Análise florística das restingas do Estado do Rio de Janeiro, p. 195-216. In L. D. de Lacerda; R. Cerqueira \& B. Turcq (eds.). Restingas: origem, estrutura e processos. Niterói, CEUFF, Universidade Federal Fluminense, $475 \mathrm{p}$.

Gagné, R. J. 1994. The gall midges of the Neotropical region. Ithaca, Cornell University. $352 \mathrm{p}$.
Gagné, R. J. 2004. A Catalog of the Cecidomyiidae (Diptera) of the world. Memoirs of the Entomological Society of Washington 25: $408 \mathrm{p}$

Gagné, R. J. \& R. Menjivar. 2008. A new species of Schizomyia (Diptera, Cecidomyiidae), a pest of Fernaldia pandurata (Apocynaceae) in Central America. Proceedings of the Entomological Society of Washington 110: 284-291

Maia, V. C. 2001. The gall midges (Diptera, Cecidomyiidae) from three restinga of Rio de Janeiro State, Brazil. Revista Brasileira de Zoologia 18: 583-629.

Maia, V. C. \& G. W. Fernandes. 2005. Two new species of Asphondyliini (Diptera, Cecidomyiidae) associated with Bauhinia brevipes (Fabaceae). Zootaxa 1091: 27-40

Maia, V. C. \& U. P. de Oliveira. 2007. Uma nova espécie de Cecidomyiidae (Diptera) associada com Sebastiania glandulosa (Euphorbiaceae). Iheringia, série Zoológica 97: 97-101.

Recebido em 02/10/2008; aceito em 05/06/2009 